\title{
Эффект Пула-Френкеля и возможность его применения для прогнозирования радиационного накопления заряда В термическом диоксиде кремния
}

\author{
(C) А.А. Ширяев ${ }^{1}$, В.М. Воротынцев ${ }^{2}$, Е.Л. Шоболов ${ }^{1}$ \\ ${ }^{1}$ Федеральный научно-производственный центр \\ „Научно-исследовательский институт измерительных систем им. Ю.Е. Седакова“, \\ 603137 Нижний Новгород, Россия \\ ${ }^{2}$ Нижегородский государственный технический университет им. Р.Е. Алексеева, \\ 603950 Нижний Новгород, Россия \\ E-mail: alsh92@rambler.ru
}

(Получена 7 ноября 2017 г. Принята к печати 29 ноября 2017 г.)

\begin{abstract}
Предложено применить эффект Пула-Френкеля для прогнозирования радиационно-индуцированного накопления заряда в термическом диоксиде кремния. Были рассмотрены различные механизмы электропроводности термического диоксида кремния, определены условия возникновения в нем эффекта ПулаФренкеля и рассчитаны характеристики донорных центров, участвующих в электропроводности ПулаФренкеля. Определен уровень донорных центров с энергией 2.34 эВ ниже дна зоны проводимости и получена концентрация ионизированных донорных центров, равная $1.0 \cdot 10^{9} \mathrm{~cm}^{-3}$ при температуре $400 \mathrm{~K}$ и напряженности поля $10 \mathrm{MB} / \mathrm{cm}$. Сделано заключение, что эффект Пула-Френкеля можно применить не для прогнозирования абсолютного значения радиационно-индуцированного заряда, а для сравнения образцов по способности его накапливать.
\end{abstract}

DOI: 10.21883/FTP.2018.09.46143.8762

\section{1. Введение}

Одной из основных причин ограничения дозовой радиационной стойкости микросхем на основе комплементарной структуры металл-оксид-полупроводник (КМОП), изготовленных с использованием структур кремний-на-изоляторе (КНИ - $[1,2])$, является формирование донного паразитного $n$-канального транзистора у дна $p$-кармана транзисторной структуры на границе раздела „приборный слой-захороненный оксид“ вследствие радиационно-индуцированного накопления положительного заряда в захороненном оксиде. Этот процесс обусловлен наличием в захороненном оксиде дырочных ловушек, причем величина накопленного в захороненном оксиде положительного заряда при воздействии ионизирующего излучения (ИИ) определяется в первую очередь концентрацией имеющихся в оксиде дырочных ловушек (дефектностью оксида) [3], которая может сильно варьироваться в рамках единого технологического процесса [4]. В связи с этим с целью прогнозирования радиационной стойкости микросхем, определения требований к уровню дефектности захороненного оксида и анализа его влияния на радиационную стойкость КМОПмикросхем необходима разработка методов контроля параметров этих ловушек (их концентрации, сечения захвата и пространственного распределения).

Основной метод, который используется для этих целей (например, [5-12]), заключается в измерении радиационно-индуцированного сдвига порогового напряжения донного паразитного транзистора или напряжения плоских зон структуры КНИ - величин, напрямую определяющихся данными параметрами ловушек.
Однако разработка альтернативных методов, особенно неразрушающих, не использующих ионизирующее излучение, может открыть новые возможности в области контроля качества и обеспечения радиационной стойкости полупроводниковых приборов. Обзору таких методов посвящена работа [13]. Такой метод может найти применение, например, для повышения точности моделирования радиационной стойкости микросхем [14], оптимизации процесса изготовления структур КНИ, обеспечения применения специальных технологических методов предотвращения образования паразитного канала $[15,16]$, а также отбраковки структур КНИ.

В работах [17-19] встречаются упоминания о наблюдаемом в диоксиде кремния механизме электропроводности Пула-Френкеля, при котором плотность тока определяется концентрацией и энергетическим положением донорных центров. Эти наблюдения носили случайный характер и не были направлены на прогнозирование радиационно-индуцированного накопления заряда в захороненном оксиде структур КНИ. В связи с этим целью данной статьи являлся анализ условий для возникновения эффекта Пула-Френкеля в термическом диоксиде кремния и возможности его применения для прогнозирования радиационного накопления заряда.

\section{2. Методика эксперимента}

Исследуемыми образцами являлись $n$-канальные МОП-транзисторы с площадью и толщиной подзатворного диэлектрика $80 \times 6$ мкм $^{2}$ и 35 нм соответственно. C помощью параметрического анализатора полупро- 
водниковых приборов и зондовой системы измерялись вольт-амперные характеристики (BAX) подзатворного диэлектрика. Затвор заземлялся, на подложку подавалось напряжение от 0 до $40 \mathrm{~B}$ с шагом 1 и $0.1 \mathrm{~B}$. Измерения ВАХ проводились при температурах 325 , 350 и $400 \mathrm{~K}$.

\section{3. Экспериментальные результаты}

На рис. 1 представлены зависимости плотности тока $J$ подзатворного диэлектрика от напряженности электрического поля $E$ диэлектрика, полученные на основе измеренных ВАХ. Видно, что кривые можно разделить на три участка, связанных, по-видимому, с тремя разными механизмами электропроводности.

Поскольку зависимость $J(E)$ линейна в диапазоне от 0 до $6 \mathrm{MB} / \mathrm{cm}$ (рис. 2), инжектирующие контакты отсутствуют и толщина диэлектрика слишком велика для прямого туннелирования, можно предположить, что в этом диапазоне проводимость диэлектрика описывается законом Ома, а другие механизмы электропроводности [20] не проявляются.

Омическая зависимость, показанная на рис. 2, описывается следующей формулой:

$$
J=n q \mu E
$$

где $q-$ элементарный заряд, $\mu-$ подвижность электронов в диэлектрике, $n-$ концентрация электронов в зоне проводимости диэлектрика, $E$ - напряженность электрического поля в подзатворном диэлектрике. Величина $n$ определяется следующей формулой:

$$
n=N_{C} \exp \left(-\frac{E_{C}-E_{\mathrm{F}}}{k T}\right),
$$

где $N_{C}$ - плотность квантовых состояний в зоне проводимости диэлектрика, $E_{C}-$ уровень дна зоны проводимости диэлектрика, $E_{\mathrm{F}}-$ уровень Ферми в диэлектрике, $k$ - постоянная Больцмана, $T$ - температура.

В формуле (1) не учитывается составляющая дырочной проводимости, поскольку она пренебрежимо мала (подвижность дырок в диоксиде кремния на 6 порядков меньше подвижности электронов).

В качестве механизма электропроводности на участке II кривых, показанных на рис. 1, был предположен механизм Пула-Френкеля, поскольку, согласно работам $[17,20]$, в диоксиде кремния он наблюдался примерно в этом диапазоне напряженностей.

В случае механизма электропроводности ПулаФренкеля $[20,21]$ зависимость плотности тока диэлектрика от напряженности электрического поля в нем устанавливается следующей формулой:

$$
J=q \mu E N_{D}(T, E),
$$

где $q$ - элементарный заряд, $\mu-$ подвижность электронов в диэлектрике $\left(20 \mathrm{~cm}^{2} /(\mathrm{B} \cdot \mathrm{c})-\right.$ в случае термического диоксида кремния [22] $), N_{D}(T, E)$ - концентрация ионизированных донорных центров в диэлектрике,

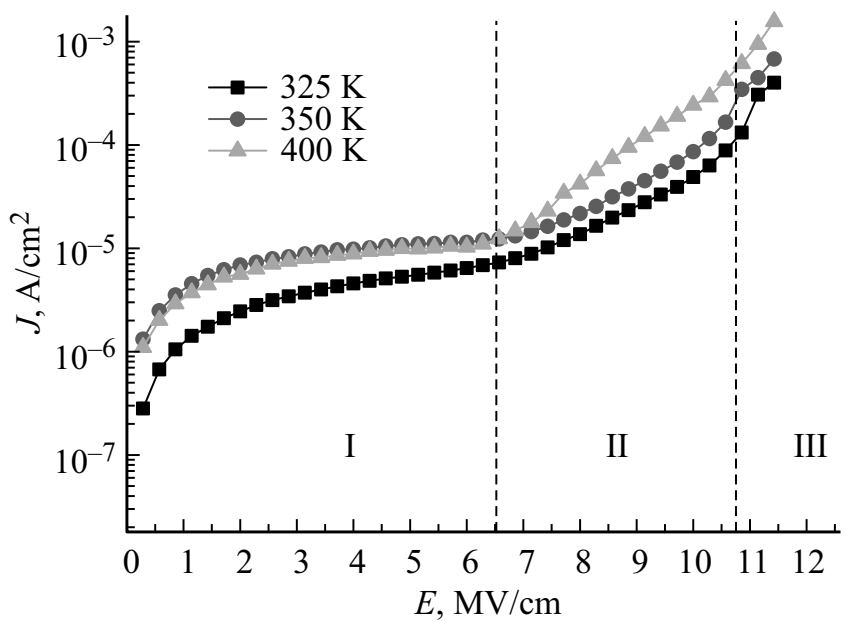

Рис. 1. Зависимости плотности тока от напряженности электрического поля подзатворного диэлектрика при разных температурах.

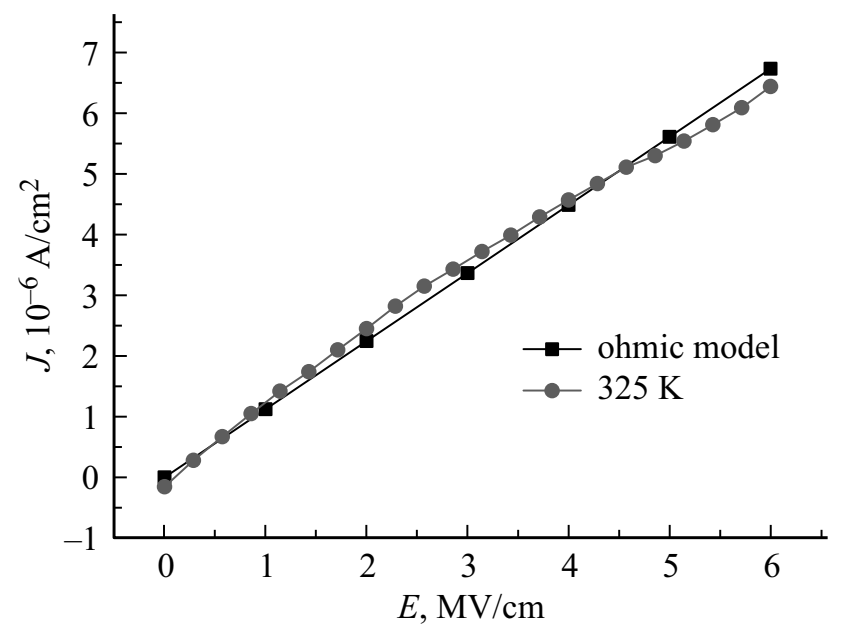

Рис. 2. Измеренная и модельная (омическая) зависимости плотности тока от напряженности электрического поля подзатворного диэлектрика при температуре $325 \mathrm{~K}$.

зависящая от температуры $T$ и напряженности поля $E$ по следующей формуле:

$$
N_{D}=N_{C} \exp \left(-\frac{q \varphi-\sqrt{\frac{q^{3} E}{\pi \varepsilon_{0} \varepsilon}}}{k T}\right),
$$

где $N_{C}$ - плотность квантовых состояний в зоне проводимости диэлектрика $\left(\sim 1.5 \cdot 10^{23} \mathrm{~cm}^{-3}-\right.$ в случае термического диоксида кремния [23]), $\varphi$ - уровень донорных центров в диэлектрике (относительно дна зоны проводимости), $\varepsilon_{0}$ - электрическая постоянная, $\varepsilon-$ относительная диэлектрическая проницаемость диэлектрика, $k$ - постоянная Больцмана.

Формулы (3) и (4) были получены на основе данных работ [20,21] с учетом следуюшего допущения: в ди- 
электрике помимо центров, обеспечивающих омический механизм электропроводности (при малых $E$ ), присутствуют только донорные центры с уровнем энергии $\varphi$, обеспечивающие электропроводность Пула-Френкеля в определенном диапазоне $E$.

На рис. 3 представлены зависимости $\ln (J / E)$ от $E^{1 / 2}$, рассчитанные из измеренных ВАХ подзатворного диэлектрика, и эта же зависимость, смоделированная по формулам (3) и (4) для температуры $400 \mathrm{~K}$. Следует отметить, что наилучшее совпадение было достигнуто для таких концентраций ионизированных центров $N_{D}$, которым соответствует уровень 2.34 эВ. При этом максимальная концентрация $N_{D}$, полученная при напряженности $10 \mathrm{MB} / \mathrm{cm}$ и температуре $400 \mathrm{~K}$, составила $1.0 \cdot 10^{9} \mathrm{~cm}^{-3}$.

Рассмотрим область III при $E>10 \mathrm{MB} / \mathrm{cm}$ $\left(E^{1 / 2}>3.2(\mathrm{MB} / \mathrm{cm})^{1 / 2}\right)$. Согласно данным работы [24], в термическом диоксиде кремния в сильных электрических полях $(E>10 \mathrm{MB} / \mathrm{cm})$ преобладает туннельный механизм электропроводности Фаулера-Нордгейма, при котором плотность тока определяется следующей формулой:

$$
J=\frac{q^{3} E^{2}}{8 \pi h q \varphi_{B}} \exp \left(-\frac{8 \pi\left(2 q m_{T}^{*}\right)^{1 / 2}}{3 h E} \varphi_{B}^{3 / 2}\right),
$$

где $h$ - постоянная Планка, $\varphi_{B}-$ энергетический барьер между подложкой и поликремниевым затвором (верхней обкладкой конденсатора), $m_{T}^{*}-$ туннельная эффективная масса электронов в диэлектрике. В нашем случае экспериментальные характеристики в соответствующем диапазоне $E\left(E^{-1}<0.1(\mathrm{MB} / \mathrm{cm})^{-1}\right)$ достаточно хорошо описываются моделью ФаулераНордгейма, как видно из рис. 4. Принимая во внимание то, что измеренная плотность тока при $E>10 \mathrm{MB} / \mathrm{cm}$

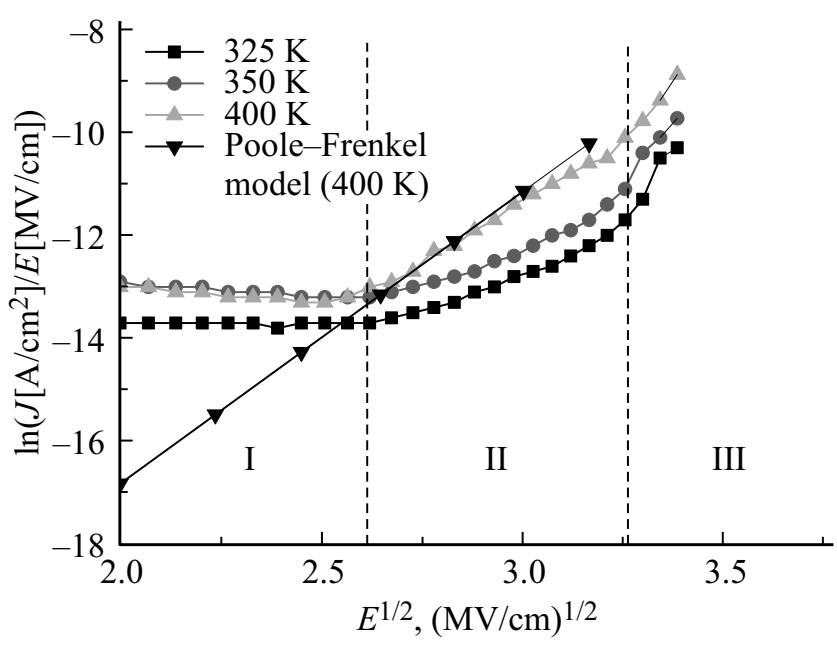

Рис. 3. Зависимости $\ln (J / E)$ от $E^{1 / 2}$, пересчитанные из измеренных $\mathrm{BAX}$ подзатворного диэлектрика, при разных температурах, и эта же зависимость, смоделированная по формулам (3) и (4) для температуры $400 \mathrm{~K}$.

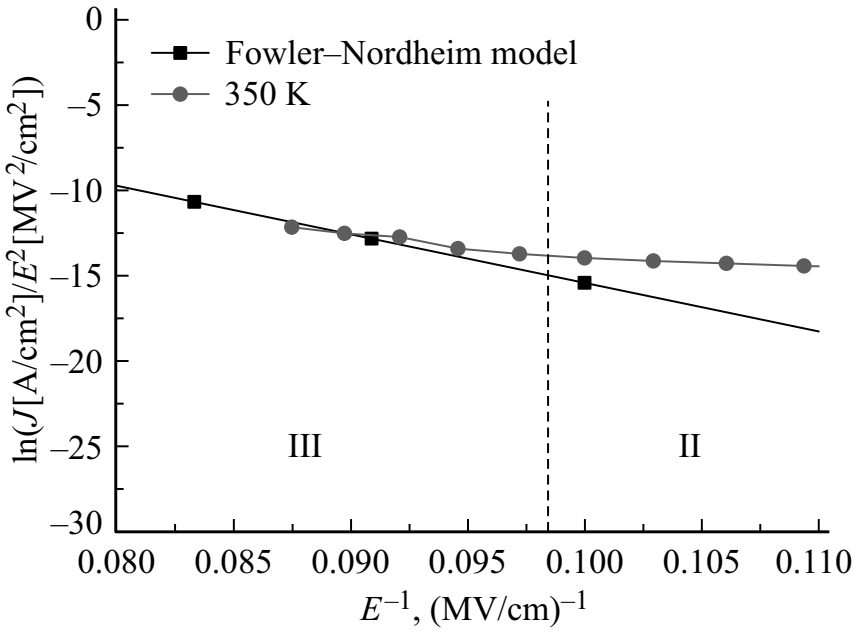

Рис. 4. Зависимость $\ln \left(J / E^{2}\right)$ от $E^{-1}$, рассчитанная из измеренной BAX подзатворного диэлектрика, при температуре $350 \mathrm{~K}$, и эта же зависимость, смоделированная по формуле Фаулера-Нордгейма (5).

слабо зависит от температуры, можно сделать вывод, что действительно наблюдается туннелирование Фаулера-Нордгейма. Следует отметить, что наилучшее совпадение характеристик на рис. 4 было достигнуто при $\varphi_{B}=3.45$ эВ, что соответствует данным работы [20].

\section{4. Обсуждение полученных результатов}

Итак, эффект Пула-Френкеля в термическом оксиде кремния толщиной 35 нм и площадью $80 \times 6$ мкм наблюдается при напряженностях электрического поля от 6 до $10 \mathrm{MB} / \mathrm{cm}$ во всем исследованном диапазоне температур (от 325 до $400 \mathrm{~K}$ ). При этом удалось получить информацию о том, каково энергетическое положение дырочных ловушек в запрещенной зоне диэлектрика и какова концентрация ионизированных дырочных ловушек в зависимости от температуры и напряженности поля.

В литературе существуют разные мнения о том, какие центры в термическом $\mathrm{SiO}_{2}$ являются основными ловушками для дырок. Так, например, в [25-27] основными называют трехвалентный кремний и межузельный кислород, а в $[28,29]$ - вакансию кислорода. В данной работе был экспериментально определен уровень с энергией $\varphi=2.34$ эВ, по-видимому соответствующий верхнему уровню вакансии кислорода ( $E_{\gamma}^{\prime}$-центру) [26].

В настоящей работе концентрация ионизированных донорных центров, участвовавших в проводимости Пула-Френкеля, составила $\sim 10^{9} \mathrm{~cm}^{-3}$ при напряженности $10 \mathrm{MB} / \mathrm{cm}$ и температуре $400 \mathrm{~K}$. В [27] упоминается о том, что в процессе воздействия $\gamma$-излучением на термический $\mathrm{SiO}_{2}$ концентрация $E^{\prime}$-центров достигает 
насыщения при значении $10^{18} \mathrm{~cm}^{-3}$. Это говорит о том, что в проводимости Пула-Френкеля участвует лишь незначительная часть донорных центров. Поэтому результаты измерений проводимости Пула-Френкеля не удастся использовать для прогнозирования абсолютного значения радиационно-индуцированного заряда. Следует провести дополнительные исследования для определения возможности сравнения образцов диоксида кремния по способоности накапливать заряд на основании измерений проводимости Пула-Френкеля.

Следует отметить, что рассмотренный в данной статье метод можно считать неразрушающим, но при этом необходимо учитывать, что в случае участия в проводимости механизма Фаулера-Нордгейма возможно накопление заряда и образование новых центров в диэлектрике, а также образование поверхностных состояний на границе диэлектрика и полупроводника [30].

\section{5. Заключение}

В данной статье показано наличие эффекта ПулаФренкеля в термическом диоксиде кремния и сделано предположение о возможности его использования для прогнозирования накопления в диэлектрике радиационно-индуцированного заряда. Было установлено, что механизм электропроводности Пула-Френкеля может наблюдаться при напряженности $6-10 \mathrm{MB} / \mathrm{cm}$ и температурах $325-400 \mathrm{~K}$. При этом можно определить энергетический уровень и концентрацию участвующих в проводимости донорных центров диоксида кремния. Был получен уровень с энергией 2.34 эВ относительно дна зоны проводимости диэлектрика, видимо относящийся к вакансиям кислорода. Максимальная концентрация участвующих в проводимости донорных центров составила $10^{9} \mathrm{~cm}^{-3}$.

\section{Список литературы}

[1] G.K. Celler, S. Cristoloveanu. J. Appl. Phys., 93 (9), 4955 (2003).

[2] А.Л. Асеев, В.П. Попов, В.П. Володин, В.Н. Марютин. Нано- и микросистемная техника, 9, 23 (2002).

[3] А.Ю. Никифоров, В.А. Телец, А.И. Чумаков. Радиационные эбфекты в КМОП ИС (М., Радио и связь, 1994).

[4] И.Б. Яшанин, Г.Г. Давыдов, А.Ю. Никифоров, Ю.М. Московская. Изв. вузов. Электроника, 5 (97), 11 (2012).

[5] T. Ouisse, S. Cristoloveanu, G. Borel. IEEE Electron Dev. Lett., 12 (6), 312 (1991).

[6] C.A. Pennise, H.A. Boesch. IEEE Trans. Nucl. Sci., 37 (6), 1990 (1990).

[7] R.E. Stahlbush, G.J. Campisi, J.B. McKitterick, W.P. Maszara, P. Roitman, G.A. Brown. IEEE Trans. Nucl. Sci., 39 (6), 2086 (1992).

[8] R.E. Stahlbush. IEEE Trans. Nucl. Sci., 43 (6), 2627 (1996).

[9] R.E. Stahlbush. IEEE Trans. Nucl. Sci., 44 (6), 2106 (1997).
[10] О.П. Гуськова, В.М. Воротынцев, Е.Л. Шоболов, Н.Д. Абросимова. Изв. вузов. Матер. электрон. техн., $4(60), 28$ (2012).

[11] Д.В. Николаев, И.В. Антонова, О.В. Наумова, В.П. Попов, С.А. Смагулова. ФТП, 37 (4), 443 (2003).

[12] А.Ю. Аскинази, А.П. Барабан, В.А. Дмитриев, Л.В. Милоглядова. Письма ЖТФ, 28 (23), 23 (2002).

[13] А.А. Ширяев, Е.Л. Шоболов, В.А. Герасимов. В сб.: ХХІ Нижегородская сессия молодых ученых. Технические науки: матер. докл., под ред. И.А. Зверевой (Княгинино, НГИЭУ, 2016) с. 105.

[14] К.О. Петросянц, Е.В. Орехов, Л.М. Самбурский, И.А. Харитонов, А.П. Ятманов. Изв. вузов. Электроника, 2 (82), 81 (2010).

[15] О.П. Гуськова, В.М. Воротынцев, Н.Д. Абросимова, Е.Л. Шоболов, М.Н. Минеев. Неорг. матер., 48 (3), 272 (2012).

[16] А.В. Амирханов, С.И. Волков, А.А. Глушко, Л.А. Зинченко, В.В. Макарчук, В.А. Шахнов. Микроэлектроника, 45 (4), 252 (2016).

[17] S. Mayo, J.S. Suehle, P. Roitman. J. Appl. Phys., 74, 4113 (1993).

[18] H. Krause, R. Grünler. Phys. Status Solidi, 42 (1), 149 (1977).

[19] S.K. Gupta, A. Azam, J. Akhtar. Pramana J. Phys., 74 (2), 325 (2010).

[20] F.C. Chiu. Adv. Mater. Sci. Engin., 2014, 578168 (2014).

[21] J.G. Simmons. J. Phys. D: Appl. Phys., 4 (5), 613 (1971).

[22] Г.И. Зебрев. Радиационные эфбекты в кремниевых интегральных схемах высокой степени интеграции (М., НИЯУ МИФИ, 2010).

[23] C. Sevik, C. Bulutay. J. Mater. Sci., 42 (16), 6555 (2007).

[24] B.D. Salvo, G. Ghibaudo, G. Panabnakakis, B. Guillaumo, G. Reimbold. Microelectron. Reliab., 39 (6-7), 797 (1999).

[25] Ф.П. Коршунов, Ю.В. Богатырев, В.А. Вавилов. Воздействие радиации на интегральные микросхемы (Минск, Наука и техника, 1986).

[26] C.T. Sah. IEEE Trans. Nucl. Sci., 23 (6), 1563 (1976).

[27] В.С. Першенков, В.Д. Попов, А.В. Шальнов. Поверхностные радиационные эфбекты в элементах интегральных микросхем (М., Энергоатомиздат, 1988).

[28] S.T. Pantelides, Z.Y. Lu, C. Nicklaw, T. Bakos, S.N. Rashkeev, D.M. Fleetwood, R.D. Schrimpf. J. Non-Cryst. Sol., 354 (2-9), 217 (2008).

[29] К.И. Таперо, В.Н. Улимов, А.М. Членов. Радиационные эбфекты в кремниевых интегральных схемах космического применения (М., БИНОМ. Лаборатория знаний, 2014).

[30] B. Balland, C. Plossu, S. Bardy Balland. Thin Sol. Films, 148 (2), 149 (1987).

Редактор Г.А. Оганесян 


\title{
Poole-Frenkel effect and opportunity of its application for radiation charge build up prediction in thermal silicon dioxide
}

\author{
A.A. Shiryaev ${ }^{1}$, V.M. Vorotyntsev ${ }^{2}$, E.L. Shobolov ${ }^{1}$ \\ ${ }^{1}$ Research and Development Center, \\ Sedakov Measuring Systems Research Institute, \\ 603137 Nizhny Novgorod, Russia \\ ${ }^{2}$ Alekseev Nizhny Novgorod State Technical University, \\ 603950 Nizhny Novgorod, Russia
}

\begin{abstract}
In this work application of Poole-Frenkel effect for radiation induced charge build up prediction in thermal silicon dioxide was proposed. Various conduction mechanisms in thermal silicon dioxide were considered, conditions for Poole-Frenkel effect were determined and characteristics of donor centers participating in Poole-Frenkel conduction were calculated. A donor center level of $2.34 \mathrm{eV}$ below the conduction band was determined and concentration of ionized donor centers of $1.0 \cdot 10^{9} \mathrm{~cm}^{-3}$ at $400 \mathrm{~K}$ and $10 \mathrm{MV} / \mathrm{cm}$ was obtained. A conclusion was made that PooleFrenkel effect can be used not for prediction of radiation induced charge build up absolute value but for comparison of samples by charge build up ability.
\end{abstract}

